\title{
Longitudinal Trajectory of the Relationship Between Self-esteem and Substance Use from Adolescence to Young Adulthood
}

Chung Gun Lee, PhD, Dong-Chul Seo, PhD, Mohammad R. Torabi, PhD, David K. Lohrmann, $\mathrm{PhD}$, and Tae Min Song, $\mathrm{PhD}$

Chung Gun Lee, PhD

Assistant Professor

Department of Physical Education

Seoul National University

1 Gwanak-ro, Gwanak-gu

Seoul 08826, South Korea

Email: cg181@snu.ac.kr

Dong-Chul Seo, PhD, FAAHB (Corresponding Author)

Professor

Department of Applied Health Science

Indiana University School of Public Health

Suite 116, 1025 East 7th Street

Bloomington, IN 47405-7109, USA

Phone: 812-855-9379, Fax: 812-855-3936, E-mail: seo@indiana.edu

Mohammad R. Torabi, PhD

Professor and Dean

Indiana University School of Public Health

1025 East 7th Street

Bloomington, IN 47405-7109, USA

E-mail: torabi@indiana.edu

David K. Lohrmann, PhD

Professor and Department Chair

Department of Applied Health Science

Indiana University School of Public Health

1025 East 7th Street

Bloomington, IN 47405-7109, USA

E-mail: dlohrman@indiana.edu

Tae Min Song, $\mathrm{PhD}$

Assistant Professor

Department of Health Management

Sahmyook University

815, Hwarang-ro, Nowon-gu,

Seoul 01795, South Korea

E-mail: tmsong@kihasa.re.kr 
Running Head: self-esteem and substance use

Abstract word count: 149

Text word count: 2,907

Reference word count: 733

Number of references: 30

Number of tables: 2

Number of figures: 0 


\title{
Longitudinal Trajectory of the Relationship Between Self-esteem and Substance Use from Adolescence to Young Adulthood
}

\begin{abstract}
BACKGROUND: To examine the longitudinal trajectory of substance use (binge drinking, marijuana use, and cocaine use) in relation to self-esteem from adolescence to young adulthood. METHODS: Generalized estimating equation models were fit using SAS to investigate changes in the relation between self-esteem and each substance use (binge drinking, marijuana use, and cocaine use) from adolescence to young adulthood. Data were drawn from the 3 waves of the National Longitudinal Study of Adolescent Health, a nationally representative sample of middle and high school students in the United States $(\mathrm{N}=6,504)$.

RESULTS: Self-esteem was a significant predictor for the use of all three substances at 15 years of age (ps <.001). However, at age 21 , self-esteem no longer predicted binge drinking and marijuana use in the controlled model.
\end{abstract}

CONCLUSIONS: It appears that self-esteem loses its protective role against substance use except cocaine use as adolescents transition to young adults.

Keywords: self-esteem; substance use; adolescents; young adults. 
Adolescence and young adulthood have been identified as critical periods for use of substances, such as alcohol, marijuana, and cocaine. ${ }^{1}$ According to the Monitoring the Future study, the trajectories of 30-day prevalence of marijuana and cocaine use peak at about age 18 $(20.6 \%)$ and 23 years $(2.6 \%)$, respectively. ${ }^{2}$ The Monitoring the Future study also shows that the trajectory for prevalence of binge drinking peaking at about age $23(41.7 \%){ }^{2}$ Substance use is an important public health problem because approximately 85,000 deaths per year are attributable to alcohol drinking and about 17,000 deaths each year to illicit drug use. ${ }^{3,4}$ Moreover, alcohol drinking and illicit drug use incur tremendous economic cost ( $\$ 224$ billion and $\$ 193$ billion, respectively), due to premature death, crime, increased medical expenses, and lower productivity. ${ }^{4,5}$ Investigating contributory factors associated with substance use or abuse is critical to development of effective interventions for preventing substance use among adolescents and young adults.

Self-esteem has been identified as an important contributory factor to substance use or abuse. ${ }^{6-12}$ Self-esteem refers to the degree to which individuals value, like, respect, and accept themselves ${ }^{13}$ and is widely considered to be one of the critical elements that affect future behavioral choice and action. ${ }^{14,15}$ According to the self-derogation theory, people who experience low levels of self-esteem are more likely to engage in deviant behaviors because they are trying to increase their self-esteem by disobeying legal standards. ${ }^{16}$ Given the role of selfesteem in deviant behavior, a number of preventive intervention programs designed to prevent youth substance use have sought to improve participants' self-esteem. ${ }^{6}$ As such, researchers have attempted to investigate the relationship between self-esteem and substance use among adolescents and young adults..$^{7-12,17-19}$ Although many of these studies reported a negative relationship between self-esteem and substance use, ${ }^{7-12}$ some found no significant relationship. ${ }^{17-}$ 
${ }^{19}$ These inconsistencies may be due to different target populations, settings, covariates, and measures of substance use. To date, research on this topic among young adults is scarce, ${ }^{17}$ and no studies have investigated changes in the relationship between self-esteem and substance use from adolescence to young adulthood.

This study attempts to analyze a nationally representative sample of middle and high school students in the United States and examine the longitudinal trajectory of binge drinking, marijuana use, and cocaine use in relation to self-esteem from adolescence to young adulthood, a period during which youth are vulnerable to substance use. ${ }^{1}$ Based on the self-derogation theory ${ }^{9}$ and the results of previous studies, ${ }^{11,12,14-17}$ we hypothesized that the higher the selfesteem, the lower the probability of using substances (binge drinking, marijuana use, and cocaine use) across adolescence and young adulthood. We also hypothesized that the strength of the relationship between self-esteem and substance use would become weaker with age for all three substances. Given that alcohol use is legal at age 21 in the United States and that several states have made marijuana use legal for adults aged 21 years or older, ${ }^{20}$ the extent to which the use of these substances is perceived as a deviant or undesirable behavior would erode once a person reaches or nears age 21 . Additionally, the rapid increase in the use prevalence of these

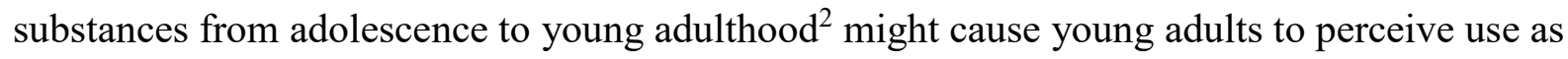
normative rather than delinquent or norm-violative behaviors. ${ }^{21}$ Thus, the hypothesis that the strength of the relationship between self-esteem and substance use would become weaker with age appeared to be warranted. Finally, we hypothesized that, even when controlling for selfesteem and age, boys show a higher rate of increase in use of these substances than girls during the transition from adolescence to young adulthood. ${ }^{22-25}$ 


\section{METHODS}

\section{Participants}

The data source for this study is the National Longitudinal Study of Adolescent Health (Add Health) data, a four-wave nationally representative longitudinal study of middle and high school students (7th through 12th grade) in the United States. Add Health included every high school in the United States with more than 30 enrollees and the 11th grade in the primary sampling frame. These high schools were stratified by size, ethnic mix, school type, urbanicity, and region. Using systematic random sampling, 80 high schools were then selected and more than $70 \%$ of these high schools were recruited. Middle schools in the United States that sent graduates to already recruited high schools and included 7th grade were also recruited, yielding a total sample of 134 schools. After stratification in each school by grade and sex, students were randomly chosen from official school rosters. From April to December in 1995, the first in-home interviews (wave 1) were conducted and approximately $79 \%$ of randomly selected students completed interviews $(\mathrm{N}=20,745)$. The first follow-up interviews (wave 2) were conducted 1 year later $(\mathrm{N}=14,738)$. The second follow-up interviews (wave 3 ) were conducted 5 years after wave $2(\mathrm{~N}=15,197)$. The third follow-up interviews (wave 4) were conducted 6 years after wave $3(\mathrm{~N}=15,701)$. Additional information about Add Health data is reported elsewhere. ${ }^{26}$ A full 6 years after the initial interview, wave 1 through 3 public-use datasets $(\mathrm{N}=6,504)$ were analyzed in this study because self-esteem measures were not available in wave 4 .

\section{Instrumentation}

Binge drinking was assessed via the question, "Over the past 12 months, on how many days did you drink five or more drinks in a row?" Responses were categorized into "1 or more 
days" (coded as 1 ) and "0 days" (coded as 0 ). Marijuana and cocaine use was assessed by asking the frequency of use during the past 30 days. Responses were categorized into " 1 or more times" (coded as 1) and "0 times" (coded as 0 ). Self-esteem was assessed by the following 4 items that were measured throughout three study waves ${ }^{27}($ Cronbach's alpha $=.72)$ : "You have a lot of good qualities," "You have a lot to be proud of," "You like yourself just the way you are," and "You felt that you were just as good as other people." The first three items were rated on a 5point Likert scale ranging from 1 (strongly disagree) to 5 (Strongly agree). The response options for the last item were 1 (never or rarely), 2 (sometimes), 3 (a lot of the time), and 4 (most of the time or all of the time). Due to the differences in the response options for the self-esteem scale, the responses were standardized before the mean of the 4 items was computed. Demographic variables included age and sex (boys and girls). Age was calculated by subtracting birth date from interview date.

\section{Data Analysis}

Analyses were performed using SAS version 9.3 (SAS Institute Inc., Cary, NC). All variables were initially examined via descriptive statistics and bivariate analyses. Generalized estimating equation (GEE) models with unstructured correlation matrix were fit using GENMOD procedure to investigate changes in the relation between self-esteem and each substance use (binge drinking, marijuana use, and cocaine use) from adolescence to young adulthood. The correlations within repeated measures were accounted for by using REPEATED statement. All the GEE models accounted for grand sample weight using WEIGHT statement. Each type of substance use served as the dependent variable. Self-esteem, age * sex, and age * self-esteem were major independent variables. Age was centered at 15 years (the mean age of the 
participants at wave 1) for Model 1 and 21 years (the mean age of the participants at wave 3) for Model 2 to help interpret analysis results. Both linear and quadratic terms of age were included in the model.

\section{RESULTS}

\section{Descriptive statistics}

Table 1 presents characteristics of participants at each wave. The average age was 15 years at wave 1, 16 years at wave 2, and 21 years at wave 3 . Approximately $51 \%$ or 3,356 of the participants were girls. For both boys and girls, significant increases in self-esteem occurred along with increases in the proportion who engaged in binge drinking ( $29 \%$ to $58 \%$ for boys, $23 \%$ to $40 \%$ for girls), marijuana use (14\% to $27 \%$ for boys, $12 \%$ to $17 \%$ for girls), and cocaine use ( $2 \%$ to $4 \%$ for boys, $1 \%$ to $2 \%$ for girls) as participants aged from wave 1 to wave 3 (ps $<$ $.001)$.

$<<$ Insert Table 1 about here $>>$

\section{Trajectory of substance use in relation to self-esteem}

Table 2 describes the results of GEE models investigating a longitudinal trajectory of each substance use (binge drinking, marijuana use, and cocaine use) from adolescence to young adulthood. An upward longitudinal trend in binge drinking, marijuana use, and cocaine use materialized with age $(\mathrm{ps}<.001)$. The age trajectory of binge drinking and marijuana use was both linear and quadratic, whereas that of cocaine use was linear. This means that the rate at which binge drinking and marijuana use increased was more rapid earlier than later in time during the transition from adolescence to young adulthood. Self-esteem was a significant predictor for the use of all three substances at 15 years of age $(\mathrm{ps}<.001)$. However, the 
relationship between self-esteem and binge drinking $(b=0.043, p<.001)$, marijuana use $(b=$ $0.054, \mathrm{p}<.001)$, and cocaine use $(\mathrm{b}=0.066, \mathrm{p}<.05)$ became weaker from adolescence to young adulthood. At age 21 (average age at wave 3), self-esteem was no longer able to predict binge drinking and marijuana use in the controlled model. Thus, the hypothesis that the higher the selfesteem, the lower the probability of using substances across adolescence and young adulthood was partially supported as self-esteem could not predict binge drinking and marijuana use at wave 3. And the hypothesis that the strength of the relationship between self-esteem and substance use would become weaker with age across the three substances was supported; selfesteem was still a significant predictor for cocaine use $(b=-0.318, p<.05)$ but not for binge drinking and marijuana use, at wave 3.

$$
<<\text { Insert Table } 2 \text { about here }>>
$$

Boys showed higher rates of increases in binge drinking $(b=0.108, p<.001)$ and marijuana use $(b=0.060, p<.001)$, but not in cocaine use $(b=0.022, p=.5897)$ than girls during the study period, resulting in higher sex discrepancies in the levels of binge drinking and marijuana use at wave 3 than at baseline (all ps $<.001$ ). Thus, the hypothesis that even controlling for self-esteem and age, boys show a higher rate of increase in use of these substances than girls during the transition from adolescence to young adulthood was partially supported; however, this hypothesis was not tenable for cocaine use.

\section{DISCUSSION}

To the authors' knowledge, this is the first study to examine the longitudinal trajectory of the relationship between self-esteem and substance use (binge drinking, marijuana use, and cocaine use) from adolescence to young adulthood. Given that this study analyzed longitudinal 
data spanning approximately 6 years from a nationally representative sample of middle and high school students in the United States at baseline, the findings may be generalizable to the entire United States population in the same age group. A major finding of this study was that, although there was a strong relationship between self-esteem and use of each of the three substances at adolescence, such relationship became weaker and even insignificant for binge drinking and marijuana use when study participants reached young adulthood. Findings of previous studies on self-esteem support our hypothesis that the higher the self-esteem, the lower the probability of using substances. ${ }^{11,12,14-17}$ It should be noted, however, that findings from all previous studies for samples of adolescents were confirmed in this study which likewise found a strong relationship between self-esteem and use of each of the three substances at adolescence.

These results are also consistent with the self-derogation theory which suggests that selfdevaluing experiences both lead to a loss of motivation to follow normative expectations and increase motivation to deviate from normative structures in order to improve self-esteem. ${ }^{9}$ Thus, according to the self-derogation theory, people with low self-worth might engage in excessive alcohol use or illicit drug use to enhance their self-esteem. What the present study adds to the existing literature is that the solidly strong relationship between self-esteem and substance use becomes weaker to the extent that no significant relationship remains, except for cocaine use, after transitioning from adolescence to young adulthood. This result may be in part explained by the legalization of alcohol use across the United States and marijuana use in some states for people aged 21 years or older. Legalizing alcohol and marijuana use can make such substance use seem less deviant from the social norm. If substance use were not considered to be deviant, people with low self-esteem would feel no implicit motivation to use substances because it would not involve disobeying legal standards and thereby help them enhance their perceived 
self-worth. Researchers affirm this by arguing that liberal substance use policy has been identified as one of the most important indicators of substance use normalization. ${ }^{28}$ The finding of the present study that self-esteem was significantly negatively related to cocaine use throughout the studied periods of transition further supports this notion of substance use normalization as cocaine use is an illicit drug throughout the country regardless of age. Another related possible explanation of this result is that recognition of a dramatic increase in the prevalence of substance use as adolescents grow and become young adults ${ }^{2}$ might recalibrate their perceived norm for substance use and begin to consider it a conventional rather than deviant behavior, ${ }^{21}$ leading to a weakened relationship between self-esteem and substance use.

Another finding of note was sex differences in substance use and its trajectory. Boys showed both higher levels of binge drinking and marijuana use across different ages and higher rates of increases in use of those substances than girls during the transition from adolescence to young adulthood. As for cocaine use, a similar sex difference in use prevalence was noted, but the difference between boys and girls in the rate of increase in cocaine use did not reach statistical significance, possibly because of a lack of statistical power due to small frequencies (ie, small numbers of cocaine users) relative to the sample size. The sex difference in substance use trends observed in the present study is in line with the findings of previous studies, ${ }^{22-25}$ although no clear explanation of the sex difference was provided by a single study. Some researchers argued that girls experience more social disapproval of alcohol consumption and illicit drug use than boys ${ }^{29}$ and one even argued that substance use is more stigmatized in girls than in boys. ${ }^{30}$ Taken together, it appears that social disapproval and stigmatization toward female substance use may explain part of the differences between boys and girls in substance use and its trajectory. Further research is warranted to investigate multilevel determinants to female 
substance use as well as mechanisms by which sex differences in substance use are widened during the transition from adolescence to young adulthood.

\section{Limitations}

The findings of this study are subject to limitations. First, this study used self-reported data that are susceptible to recall bias. Second, due to the nature of this study that analyzed a secondary dataset, analyses were limited to the variables that were selected by Add Health designers. Desirable future research would examine multilevel determinants to substance use in a representative sample of adolescents and prospectively follow participants up into their adulthood. Third, since the number of participants who used cocaine was relatively small across all three waves, caution is needed in interpreting cocaine-use related results. Lastly, the present study analyzed only three waves of longitudinal data, which might have limited the capacity for capturing the dynamics of the relationship between self-esteem and substance use in the study population.

\section{Conclusions}

Despite these limitations, this study contributes to the literature by documenting the longitudinal trajectory of the relationship between self-esteem and use of three substances (binge drinking, marijuana use, and cocaine use) from adolescence to young adulthood in a nationally representative sample of the United States population, which has the strength of higher generalizability compared to most other studies with nonprobability samples. Furthermore, the present study helped understand the longitudinal trajectory of the relationship between self- 
esteem and substance use as well as the heterogeneity in the trajectory between cocaine and the other two substances.

\section{IMPLICATIONS FOR SCHOOL HEALTH}

The findings of this study confirm the protective role of high levels of self-esteem against substance use for adolescents but not for young adults. This has at least two-fold implications. First, teachers' and parents' efforts to improve their respective students and children's selfesteem appear to be an effective strategy to prevent adolescents, especially those with low levels of self-esteem, from using substances among others. School health professionals can continue to make an effort to enhance students' self-esteem as well as provide evidence-based substance use prevention education to deter students from using substances. However, given the finding that the strength of the relationship between self-esteem and substance use becomes weaker with age, school health professionals need to equip adolescents with appropriate attitudes against possible substance use normalization that is often accompanied by reaching a certain age. Adolescents need to be correctly informed and constantly aware that reaching a certain age does not make them immune to harm or detriments substance use would incur. Middle and high schools should do a better job than now in preparing students against possible substance use normalization they may erroneously absorb in later years.

\section{Human Subjects Approval Statement}

This study was exempted from the review of the Institutional Review Board at the authors' institution because of the public availability of the data. 


\section{REFERENCES}

1. Stone AL, Becker LG, Huber AM, Catalano RF. Review of risk and protective factors of substance use and problem use in young adulthood. Addict Behav. 2012;37:747-775.

2. Johnston LD, O'malley PM, Bachman JG, Schulenberg JE. Monitoring the Future: National Survey Results on Drug Use, 1975-2009: Volume II: College Students and Adults Ages 19-50 (NIH Publication No. 10-7585). Bethesda, MD: National Institute on Drug Abuse; 2010. 3. Mokdad AH, Marks JS, Stroup DF, Gerberding JL. Actual causes of death in the United States, 2000. JAMA. 2004;291(10):1238-1245.

4. US Department of Health and Human Services. Healthy People 2020. Topics \& Objectives: Substance Abuse. Washington, DC: US Department of Health and Human Services; 2013.

5. US Department of Justice National Drug Intelligence Center. National Drug Threat Assessment. Johnstown, PA: US Department of Justice National Drug Intelligence Center; 2011. 6. Hunt B, Guindon MH. Alcohol and other drug use and self-esteem in young adults. In: Guindon MH, ed. Self-esteem Across The Lifespan: Issues and Interventions. New York, NY: Routledge/Taylor and Francis Group; 2010:219-229.

7. Richardson CG, Kwon J, Ratner PA. Self-esteem and the initiation of substance use among adolescents. Can J Public Health. 2013;104(1):e60-e63.

8. Mckay MT, Sumnall HR, Cole JC, Percy A. Self-esteem and self-efficacy: Association with alcohol consumption in a sample of adolescents in Northern Ireland. Drugs: Educ Prev Policy. 2012;19(1):72-80. 
9. Peterson $\mathrm{CH}$, Buser TJ, Westburg NG. Effects of familial attachment, social support, involvement, and self-esteem on youth substance use and sexual risk taking. Fam J: Couns Therap Couples Fam. 2010;18(4):369-376.

10. Zamboanga BL, Schwartz SJ, Jarvis LH, Van Tyne K. Acculturation and substance use among Hispanic early adolescents: Investigating the mediating roles of acculturative stress and self-esteem. J Prim Prev. 2009;30:315-333.

11. Boden JM, Fergusson DM, Horwood LJ. Does adolescent self-esteem predict later life outcomes? A test of the causal role of self-esteem. Dev Psychopathol. 2008;20:319-339.

12. Henderson CE, Dakof GA, Schwartz SJ, Liddle HA. Family functioning, self-concept, and severity of adolescent externalizing problems. J Child Fam Stud. 2006;15(6):719-729.

13. Rosenberg M. Conceiving the Self. New York, NY: Basic Books; 1979.

14. Leary MR, Baumeister RF. The nature and function of self-esteem: Sociometer theory. Adv Exp Soc Psychol. 2000;32:1-62.

15. Tesser A. Self-esteem. In: Brewer MB, Hewstone M, eds. Motivation and Emotion. Malden, MA: Blackwell; 2004:184-203.

16. Kaplan HB, Martin SS, Robbins C. Pathways to adolescent drug use: Self-derogation, peer influence, weakening of social controls, and early substance use. J Health Soc Behav. 1984;25:270-289.

17. Vasquez EP, Gonzalez-Guarda RM, De Santis JP. Acculturation, depression, self-esteem, and substance abuse among Hispanic men. Issues Ment Health Nurs. 2011;32(2):90-97.

18. Fisher LB, Miles IW, Austin SB, Camargo CA, Colditz GA. Predictors of initiation of alcohol use among US adolescents: findings from a prospective cohort study. Arch Pediatr Adolesc Med. 2007;161(10):959-966. 
19. Kokkevi A, Richardson C, Florescu S, Kuzman M, Stergar E. Psychosocial correlates of substance use in adolescence: A cross-national study in six European countries. Drug Alcohol Depend. 2007;86(1):67-74.

20. National alliance for model state drug laws. State marijuana laws. 2014. Available at: http://www.namsdl.org/library/1A5753E7-65BE-F4BB-A296C6C1E7349E83/. Accessed December 23, 2014.

21. Cialdini RB. Descriptive social norms as underappreciated sources of social control. Psychometrika. 2007;72(2):263-268.

22. Biehl MC, Natsuaki MN, Ge X. The influence of pubertal timing on alcohol use and heavy drinking trajectories. $J$ Youth Adolesc. 2007;36(2):153-167.

23. Duncan SC, Duncan TE, Strycker LA. Alcohol use from ages 9-16: A cohort-sequential latent growth model. Drug Alcohol Depend. 2006;81(1):71-81.

24. Mitchell CM, Novins DK, Holmes T. Marijuana use among American Indian adolescents: A growth curve analysis from ages 14 through 20 years. $J$ Am Acad Child Adolesc Psychiatry. 1999;38(1):72-78.

25. Chen P, Jacobson KC. Developmental trajectories of substance use from early adolescence to young adulthood: Gender and racial/ethnic differences. $J$ Adolesc Health. 2012;50(2):154-163.

26. Harris KM, Halpern CT, Whitsel E, Hussey J, Tabor J, Entzel P, Udry JR. The National Longitudinal Study of Adolescent Health: Research Design. Available at: http://www.cpc.unc.edu/projects/addhealth/design. Accessed January 25, 2017. 
27. Resnick MD, Bearman PS, Blum RW, Bauman KE, Harris KM, Jones J, Tabor J, et al. Protecting adolescents from harm: Findings from the National Longitudinal Study on Adolescent Health. JAMA. 1997;278(10):823-832.

28. Parker H, Williams L, Aldridge J. The normalization of 'sensible' recreational drug use: Further evidence from the North West England longitudinal study. Sociology. 2002;36(4):941964.

29. Brady KT, Randall CL. Gender differences in substance use disorders. Psychiatric Clinics of North America. 1999;22(2):241-252.

30. Blume SB. Women and alcohol: A review. JAMA. 1986;256:1467-70. 
Table 1. Descriptive Characteristics of Participants at Wave 1 to $3(\mathrm{~N}=6,504)$

\begin{tabular}{|c|c|c|c|c|c|c|c|c|c|c|c|c|}
\hline \multirow{3}{*}{ Characteristics } & \multicolumn{4}{|c|}{ Wave $1(\mathrm{~N}=6,504)$} & \multicolumn{4}{|c|}{ Wave $2(\mathrm{~N}=4,834)$} & \multicolumn{4}{|c|}{ Wave $3(\mathrm{~N}=4,882)$} \\
\hline & \multicolumn{2}{|c|}{ Boys $(n=3,147)$} & \multicolumn{2}{|c|}{ Girls $(n=3,356)$} & \multicolumn{2}{|c|}{ Boys $(n=2,315)$} & \multicolumn{2}{|c|}{ Girls $(n=2,519)$} & \multicolumn{2}{|c|}{ Boys $(n=2,253)$} & \multicolumn{2}{|c|}{ Girls $(n=2,629)$} \\
\hline & Mean & $S D$ & Mean & $S D$ & Mean & $S D$ & Mean & $S D$ & Mean & $S D$ & Mean & $S D$ \\
\hline Age, years & 15.1 & 1.6 & 14.9 & 1.6 & 16.1 & 1.6 & 15.9 & 1.6 & 21.4 & 1.7 & 21.1 & 1.7 \\
\hline \multirow{2}{*}{$\begin{array}{l}\text { Self-esteem, z- } \\
\text { score }\end{array}$} & 0.046 & 0.703 & -0.193 & 0.782 & 0.097 & 0.690 & -0.100 & 0.768 & 0.170 & 0.666 & 0.089 & 0.686 \\
\hline & $\mathrm{n}$ & $\%$ & $\mathrm{n}$ & $\%$ & $\mathrm{n}$ & $\%$ & $\mathrm{n}$ & $\%$ & $\mathrm{n}$ & $\%$ & $\mathrm{n}$ & $\%$ \\
\hline Binge drinking & 900 & 28.7 & 771 & 23.0 & 713 & 31.0 & 640 & 25.5 & 1,306 & 58.1 & 1,050 & 40.1 \\
\hline Marijuana use & 438 & 14.4 & 391 & 11.8 & 377 & 16.6 & 339 & 13.7 & 608 & 27.1 & 454 & 17.3 \\
\hline Cocaine use & 50 & 1.6 & 29 & 0.9 & 39 & 1.7 & 21 & 0.8 & 92 & 4.1 & 51 & 1.9 \\
\hline
\end{tabular}


Table 2. Generalized Estimating Equation Models Examining Trajectory of Binge Drinking, Marijuana Use, and Cocaine Use from Adolescence Through Young Adulthood $(\mathrm{N}=\mathbf{6 , 5 0 4})$

\begin{tabular}{|c|c|c|}
\hline & $\mathrm{b}$ & 95\% Confidence Interval \\
\hline \multicolumn{3}{|l|}{ Binge drinking } \\
\hline Age & $0.475^{* * *}$ & $(0.433-0.516)$ \\
\hline $\mathrm{Age}^{2}$ & $-0.032^{* * *}$ & $(-0.037-0.028)$ \\
\hline \multicolumn{3}{|l|}{ Sex } \\
\hline Boys & $0.164^{*}$ & $(0.021-0.306)$ \\
\hline \multicolumn{3}{|l|}{ Girls (ref.) } \\
\hline Self-esteem & $-0.323^{* * *}$ & $(-0.403--0.243)$ \\
\hline Age $\times$ Sex & $0.108^{* * *}$ & $(0.078-0.138)$ \\
\hline Age $\times$ Self-esteem & $0.043^{* * *}$ & $(0.023-0.064)$ \\
\hline \multicolumn{3}{|l|}{ Marijuana use } \\
\hline Age & $0.344^{* * *}$ & $(0.297-0.392)$ \\
\hline $\mathrm{Age}^{2}$ & $-0.030^{* * *}$ & $(-0.035-0.024)$ \\
\hline \multicolumn{3}{|l|}{ Sex } \\
\hline Boys & $0.204^{*}$ & $(0.031-0.377)$ \\
\hline \multicolumn{3}{|l|}{ Girls (ref.) } \\
\hline Self-esteem & $-0.414^{* * *}$ & $(-0.508--0.321)$ \\
\hline Age $\times$ Sex & $0.060^{* * *}$ & $(0.025-0.095)$ \\
\hline Age $\times$ Self-esteem & $0.054^{* * *}$ & $(0.030-0.077)$ \\
\hline \multicolumn{3}{|l|}{ Cocaine use } \\
\hline Age & $0.173^{* * *}$ & $(0.116-0.230)$ \\
\hline $\mathrm{Age}^{2}$ & -0.014 & $(-0.031-0.003)$ \\
\hline \multicolumn{3}{|l|}{ Sex } \\
\hline Boys & $0.660^{* *}$ & $(0.254-1.065)$ \\
\hline \multicolumn{3}{|l|}{ Girls (ref.) } \\
\hline Self-esteem & $-0.714^{* * *}$ & $(-1.010--0.418)$ \\
\hline Age $\times$ Sex & 0.022 & $(-0.058-0.103)$ \\
\hline Age $\times$ Self-esteem & $0.066^{*}$ & $(0.005-0.127)$ \\
\hline
\end{tabular}

